\title{
EUS in the Management of High-Risk Gastrointestinal Precancerous Lesions before Endoscopic Resection
}

\author{
Yanliu Chu M.D., Ph.D ${ }^{1}$, Ranran Wang ${ }^{1}$, Tian Li ${ }^{1}$, Xiuli Qiao ${ }^{1}$, Xiaofeng Wang ${ }^{1}$, Feng Liu ${ }^{1}$, Xiaozhong Gao ${ }^{1 *}$, Songyang Yu ${ }^{2}$ \\ ${ }^{1}$ Department of Gastroenterology, Weihai Municipal Hospital, Binzhou Medical University, Weihai 264200, Shandong Province, China \\ ${ }^{2}$ Department of Anesthesiology, Weihai Municipal Hospital, Binzhou Medical University, Weihai 264200, Shandong Province, China \\ ${ }^{*}$ Corresponding author: Xiaozhong Gao, Department of Gastroenterology, Weihai Municipal Hospital, Binzhou Medical University, Weihai 264200, Shandong \\ Province, China; Tel: +86-186-63168566; Fax: +86-631-5224816; Email: xzgaoweihai@sina.com
}

Received: April 07, 2019; Accepted: April 26, 2019; Published: May 11, 2019;

\begin{abstract}
Aim: To investigate the evaluation of EUS for the high-risk gastrointestinal precancerous lesions (HRGIPCL) before endoscopic resection.

Methods: The patients with HRGIPCL scheduled for endoscopic resection, were randomized to preoperatively performing EUS (Group A) versus without EUS (Group B). Data were prospectively collected as follows: routine endoscopic results, EUS findings, therapeutic maneuvers, resected lesion size, final diagnosis and the grades of therapeutic maneuvers.

Results: 116 patients with 156 HRGIPCL were included in Group A and 116 with 140 HRGIPCL in Group B. In terms of routine endoscopic results, resected lesion size $(1.84 \pm 1.30 \mathrm{~cm}$ in Group A vs $1.70 \pm 0.97 \mathrm{~cm}$ in Group B) and final diagnosis, no differences were found between two groups $(P>0.05)$. 207 endoscopic mucosal resection (EMR) was performed for 157 patients (114 EMR for 81 patients in Group A vs 93 for 76 in Group B), 14 endoscopic piecemeal mucosal resection (EPMR) for 14 patients (7 in Group A vs 7 in Group B), and 72 endoscopic submucosa dissection (ESD) for 67 patients (32 ESD for 30 patients in Group A vs 40 for 37 in Group B). No significant differences were observed between two groups $(P>0.05)$. 33 adverse events occurred with significant differences between two groups (11 in Group A vs 22 in Group B, $P<0.05)$. The grades of therapeutic maneuvers in Group A was higher than that in Group B $(P<0.05)$.
\end{abstract}

Conclusion: It was helpful to be evaluated by EUS for HRGIPCL before endoscopic resection.

Key Words: endoscopic ultrasonography; high-risk; gastrointestinal; precancerous lesions; low grade intraepithelial neoplasia; laterally spreading tumor; large gastrointestinal adenoma; endoscopic mucosal resection; endoscopic piecemeal mucosal resection; endoscopic submucosa dissection

\section{INTRODUCTION}

We can find the early gastrointestinal cancer and remove it through endoscopy [1-8], Can we nip in the bud, blocking the early cancer at the precancerous stage [9]?

It is a common treatment option to endoscopically find and remove the high-risk gastrointestinal precancerous lesions (HRGIPCL), for example, low grade intraepithelial neoplasia (LGIN), laterally spreading tumor (LST) and large gastrointestinal adenomas. Will endoscopic ultrasonography (EUS) be helpful preoperatively? Because, as we all know, it was usually helpful for the early malignant lesions to be valuated using EUS before endoscopic removal [10-13].

\section{MATERIALS AND METHODS}

\section{Patients}

From April 2009 to March 2015, the patients with HRGIPCL scheduled for therapeutic endoscopic intervention, were randomized to preoperatively performing EUS (Group A) versus no EUS (Group B). Based on our clinical experiences and the relevant literatures [9,14-16], we classified the following lesions as HRGIPCL: LGIN, LST
$(>1.0 \mathrm{~cm})$, sessile or rebagliati polyps (limited to tubular, tubulovillous and villous adenomas, $>1.0 \mathrm{~cm}$ ). All the lesions had undergone routine endoscopy, biopsy and histopathological examination, and the malignant ones including high grade intraepithelial neoplasia (HGIN) had been excluded from the study. This study got the approval from Weihai Municipal Hospital Ethics Committee. After each patient signed an informed consent, each endoscopic exploration began.

\section{Procedures}

All the endoscopic procedures were carried out by four endoscopists, assisted by three nurses. EUS was performed with a radial echoendoscope (Olympus GF-UM2000, Olympus Medical Systems Corp, Tokyo, Japan). Therapeutic endoscopic intervention were done using gastroscopy, colonoscopy, snare, single use electrosurgical knife [including IT Knife 2 (KD-611L), Hook Knife (KD-620LR), Dual Knife (KD-650L) and Triangle Tip Knife (KD640L), Olympus Medical Systems Corp, Tokyo, Japan)], or Hybrid Knife (ERBE Elektromedizin GmbH, Tuebingen, Germany). ERBE VIO 200D (ERBE Elektromedizin GmbH, Tuebingen, Germany), was used as Electrosurgical Generator. 
All the endoscopic explorations were conducted under intravenous anesthesia administered by two anesthesiologists: intravenous fentanyl and midazolam followed by propofol.

Data were prospectively collected as follows: age, sex, routine endoscopic results, EUS findings, therapeutic maneuvers, resected lesion size, final diagnosis, the grades of therapeutic maneuvers, and endoscopic complications.

\section{Statistical analysis}

Quantitative variables were described as mean \pm standard deviation. Kolgomorov-Smirnoff test was used to verify the normal distribution of quantitative data, and T-test was used for testing significance between quantitative variables. Chi-square test was used to detect significant difference among qualitative variables. The $P$-value under 0.05 was considered significant.

\section{RESULTS}

\section{General information}

116 patients were included in Group A and 116 in Group B. In terms of age, sex and preoperatively routine endoscopic results, no differences were found between two groups $(P>0.05)$. The above data were shown in Table 1.

Table 1. General information

\begin{tabular}{|c|c|c|c|}
\hline & Group A & Group B & $P$-value \\
\hline Total & 116 & 116 & \\
\hline Gender & & & \multirow[t]{3}{*}{0.130} \\
\hline Men & 70 & 81 & \\
\hline Women & 46 & 35 & \\
\hline Mean age (years) & $\begin{array}{c}61.66 \pm \\
10.10\end{array}$ & $\begin{array}{c}59.08 \pm \\
10.91\end{array}$ & 0.062 \\
\hline $\begin{array}{l}\text { Indication } \\
\text { (Number of patients/ lesions) }\end{array}$ & $116 / 156$ & $116 / 140$ & 0.537 \\
\hline Location of lesion & & & \multirow[t]{5}{*}{$0.523^{\mathrm{a}} / 0.233^{\mathrm{b}}$} \\
\hline Esophagus & $0 / 0$ & $1 / 1$ & \\
\hline Stomach & $23 / 25$ & $24 / 27$ & \\
\hline Duodenum & $0 / 0$ & $2 / 2$ & \\
\hline Large intestine & $93 / 131$ & $89 / 110$ & \\
\hline Pattern of Lesion & & & \multirow[t]{4}{*}{$0.299^{\mathrm{a}} / 0.517^{\prime}$} \\
\hline LST & $37 / 42$ & $32 / 36$ & \\
\hline Sessile & $74 / 100$ & $81 / 96$ & \\
\hline Rebagliati & $13 / 14$ & $7 / 8$ & \\
\hline $\begin{array}{l}\text { Preoperative pathology of } \\
\text { Lesion }\end{array}$ & & & \multirow[t]{5}{*}{$0.097^{\mathrm{a}} / 0.068$} \\
\hline LGIN & $34 / 38$ & $40 / 41$ & \\
\hline Tubular adenomas & $47 / 67$ & $59 / 70$ & \\
\hline Tubulovillous adenomas & $40 / 50$ & $27 / 29$ & \\
\hline Villous adenomas & $1 / 1$ & $0 / 0$ & \\
\hline
\end{tabular}

LST: laterally spreading tumor; LGIN: low grade intraepithelial neoplasia

${ }^{\mathrm{a}}: P$-value according to the number of patients; ${ }^{\mathrm{b}}: P$-value according to the number of lesions

\section{Therapeutic maneuvers, resected lesion size and final diagnosis}

207 endoscopic mucosal resection (EMR) was performed for 157 patients (114 EMR for 81 patients from Group A vs 93 for 76 from Group B), 14 endoscopic piecemeal mucosal resection (EPMR) for 14 patients ( 7 in Group A vs 7 in Group B), and 72 endoscopic submucosal dissection (ESD) for 67 patients (32 ESD for 30 patients belonging to Group A vs 40 for 37 belonging to Group B). There were no significant differences $(P=0.398>0.05)$. According to the preoperative EUS findings, 3 patients preferred surgical operation rather than planned endoscopic removal in Group A.

The mean size of resected lesions was $1.84 \pm 1.30 \mathrm{~cm}$ in Group A and $1.70 \pm 0.97 \mathrm{~cm}$ in Group B, without significant differences $(P=$ $0.293>0.05)$.

According to pathological diagnoses of removed specimens, including surgical specimens, final diagnoses were shown in Table 2. There were no significant differences between two groups $(P=0.096$ $>0.05)$.

\section{Grades of therapeutic maneuvers}

On the basis of the principle, that is, it was helpful for the gastrointestinal early malignant lesions to be evaluated by EUS before endoscopic resection, we developed a scoring system as shown in Table 3. According to this scoring system, the grades of therapeutic maneuvers in Group A was higher than that in Group B $(P=0.000<$ 0.05). The above data were shown in Table 4.

Table 3. The scoring system of therapeutic endoscopic maneuvers for HRGIPCL

\begin{tabular}{|l|l|l|l|l|}
\hline \multirow{2}{*}{} & \multicolumn{4}{|c|}{ Grades according to postoperative pathology } \\
\cline { 2 - 5 } & $\begin{array}{l}\text { Benign } \\
\text { lesions }\end{array}$ & HGIN & $\begin{array}{l}\text { Early } \\
\text { cancer }\end{array}$ & $\begin{array}{l}\text { Advanced } \\
\text { cancer }\end{array}$ \\
\hline Evaluation by EUS & 0 & 1 & 2 & 3 \\
\hline Without evaluation by EUS & 0 & 0 & 0 & 0 \\
\hline
\end{tabular}

HRGIPCL: high-risk gastrointestinal precancerous lesions;

HGIN: high grade intraepithelial neoplasia

Table 4. Grades of therapeutic endoscopic maneuvers for HRGIPCL in two groups

\begin{tabular}{|l|c|c|c|c|c|c|}
\hline \multirow{2}{*}{} & \multicolumn{5}{|c|}{ Grades /Number } & P-value \\
\cline { 2 - 7 } & $\begin{array}{l}\text { Benign } \\
\text { lesions }\end{array}$ & HGIN & $\begin{array}{l}\text { Early } \\
\text { cancer }\end{array}$ & $\begin{array}{l}\text { Advanced } \\
\text { cancer }\end{array}$ & Total & \\
\hline $\begin{array}{l}\text { Group } \\
\text { A }\end{array}$ & $0 / 125$ & $1 / 27$ & $2 / 2$ & $3 / 2$ & $37 / 156$ & 0.000 \\
\hline $\begin{array}{l}\text { Group } \\
\text { B }\end{array}$ & $0 / 114$ & $0 / 19$ & $0 / 5$ & $0 / 2$ & $0 / 140$ & \\
\hline
\end{tabular}

HRGIPCL: high-risk gastrointestinal precancerous lesions; HGIN: high grade intraepithelial neoplasia

\section{Adverse events}

5 cases of endoscopic procedures followed by appended surgery which included 1 early signet ring cell cancer from Group A, 2 early cancer with suspicious residual tumor and 2 advanced cancer from Group B. 
28 cases of endoscopic complications included 16 bleeding $(6$ in Group A and 10 in Group B), and 12 perforation (4 in Group A and 8 in Group B). 1 bleeding in Group B, and 3 perforation(1 in Group A and 2 in Group B ) underwent surgical operation.

In terms of complications, no significant difference were observed between the two groups $(P=0.058>0.05)$. However, 11 adverse events in Group A were less than 22 in Group B $(P=0.018<0.05)$.

\section{DISCUSSION}

Generally, EUS had better to be performed before the endoscopic resection is carried out for the early gastrointestinal cancer. Though, EUS is not usually required prior to the endoscopic removal for HRGIPCL. This is maybe due to that HRGIPCL is often considered as benign lesions by endoscopists with preconceived ideas. In fact, the socalled HRGIPCL may be just the tip of the iceberg $[9,14]$. May EUS be helpful before the therapeutic endoscopic procedures for HRGIPCL?

In our study, 46 HGIN and 11 gastrointestinal cancers were finally found in the 296 preoperative so-called HRGIPCL. Moreover, of these 11 cancers, there were 4 advanced cancers (2 from Group A and 2 from Group B). Some studies had similar findings. O’Brien MJ et al found HGIN among $35 \%$ of colorectal villous adenomas $(>1 \mathrm{~cm}$ ) [17]. Moreover, of 43 colorectal adenomas $(\geq 2.5 \mathrm{~cm})$, Elizabeth D. Euscher et al observed 5 invasive carcinoma [14].

In the Group B, these 2 advanced colorectal cancers preoperatively appeared as one LST and one sessile tubulovillous adenomas. Both of them underwent the surgery following the failed ESD. Moreover, in the Group B, one gastric early cancer after ESD and one colorectal cancer after EPMR, both accepted appended surgery because the cancer cells were observed on bottoms of resected lesions. Though, no cancer tissue were found in the postoperative specimen. However, the gratified results were observed in the Group A. Based on the preoperative EUS findings, those 2 advanced colorectal cancers being formerly regarded as sessile tubulovillous adenomas, both preferred to the surgery instead of the endoscopic resection.

Furthermore, there was such a surprised case in the Group A. One LGIN at the anterior wall of the junction of gastric body and antrum, was found by the gastroscope in his health check. A month later, he accepted the second gastroscopy, and the previous lesion area seemed to return to normal. EUS was still performed in accordance with the established procedures. The thickened hypoechoic mucous layer, with the incomplete muscularis mucosa and submucosa, was observed. Then, the jumbo biopsy was finished, and its histopathologic behaviors showed the moderately differentiated mucinous adenocarcinoma infiltrating into the submucosa. The final surgical specimens displayed the same pathological diagnosis and no lymph node metastasis.

Additionally, a large rectal LST in Group B, gave us a profound lesson. During the process of ESD, injection bleeding occurred, and endoscopic hemostasis failed, leading to hypovolemic shock, and following by surgery, because of a thick vascular broken end. In fact, ultrasonography preoperatively found a suspicious blood vessel within the thickening rectal mucosa. Unfortunately, it did not attract our enough attentions. We usually thought a crude vessel in bulky pedicle polyp. This lesson told us that EUS help to discovery the coarse vascellum hiding in the lesion, regardless of its shape, thus avoiding uncontrollable intraoperative bleeding.

However, we have to acknowledge the shortcomings of EUS [18-20]. It can usually reveal whether the cancer has invaded the muscularis propria. That is, it can distinguish the early gastrointestinal cancers from the advanced ones. Though, EUS is difficult to accurately define the depth of tumor reaching in the submucosa. So, before ESD for early cancer, if EUS says "NO", we can choose to believe EUS, and if EUS says "YES", we can choose to doubt EUS [21,22]. Before the endoscopic removal for early cancer, it is primary to preliminary screen the early cancers and advanced ones out from HRGIPCL. Obviously, EUS is qualified for this task, though the procedures and findings of EUS are all fairly subjective.

At the same time, many studies have shown that, the mucosal microstructure including the pit pattern and microvascular pattern demonstrated by chromoendoscopy and magnifying endoscopy, was very helpful to determining early gastrointestinal cancer, and identifying some early cancers suitable for endoscopic resection [23-28]. However, at present, this approach was mainly applied to esophageal cancer. It was still difficult to be used for gastric cancer and colorectal cancer. Even so, in fact, we had not yet mastered this method well. In order to be proficient in this means, it was necessary to carefully observe a large number of early gastrointestinal cancers by chromoendoscopy and magnifying endoscopy. Therefore, we thought that it was more difficult to master this method than to apply EUS for evaluating the gastrointestinal cancers. Apparently, it would be better to combine these two methods.

In summary, our study showed that EUS could help reduce the incidence of adverse events during the endoscopic removal of HRG IPCL. Thence, we thought that it was helpful to be evaluated by EUS for HRGIPCL before endoscopic resection.

Author contributions: Gao XZ, Chu YL, Wang RR, Qiao XL and Wang XF designed research; Gao XZ, Chu YL, Qiao XL, Wang XF, Wang RR, Yu SY and Liu F performed research; Chu YL, Wang RR, Li T analyzed data; Chu YL, Gao XZ, Wang RR and Li T wrote the paper.

Conflicts of interest: There are no conflicts of interest.

\section{REFERENCES}

1. Deyhle P, Largiader F, Jenny S, Fumagalli I. (1973) A method for endoscopic electroresection of sessile colonic polyps. Endoscopy, 5(1): 38-40.

2. Takuji Gotoda, Hwoon-Yong Jung. (2013) Endoscopic resection (endoscopic mucosal resection/endoscopic submucosal dissection) for early gastric cancer. Digestive Endoscopy. 25(Suppl. 1): 55-63. [Crossref]

3. Hirao M, Masuda K, Asanuma T, Naka H, Noda K, et al. (1988) Endoscopic resection of early gastric cancer and other tumors with local injection of hypertonic saline-epinephrine. Gastrointest Endosc. 34(3): 264-269. [Crossref]

4. Gotoda T, Kondo H, Ono H, Saito Y, Yamaguchi H, et al. (1999) A new endoscopic mucosal resection procedure using an insulation-tipped electrosurgical knife for rectal flat lesions: report of two cases. Gastrointest. Endosc. 50(4): 560-3. [Crossref]

5. Eguchi T, Gotoda T, Oda I, Hamanaka H, Hasuike N, et al. (2003) Is endoscopic one-piece mucosal resection essential for early gastric cancer? Dig. Endosc. 15(2): 113-16.

6. Yokoi C, Gotoda T, Hamanaka H, Oda I. (2006) Endoscopic submucosal dissection (ESD) allows curative resection of local recurrent early gastric cancer after prior endoscopic mucosal resection. Gas-trointest. Endosc. 64(2): 212-18. [Crossref]

7. Katsumi Yamamoto, Tomoki Michida, Tsutomu Nishida, Shiro Hayashi, Masafumi Naito, et al. (2015) Colorectal endoscopic submucosal dissection: Recent technical 
advances for safe and successful procedures. World J Gastrointest Endosc. 7(14): 1114-1128.

8. Miguel A Tanimoto, M Lourdes Guerrero, Yoshinori Morita, Jonathan AguirreValadez, Elisa Gomez, et al. (2015) Impact of formal training in endoscopic submucosal dissection for early gastrointestinal cancer: A systematic review and a meta-analysis. World J Gastrointest Endosc. 16; 7(4): 417-428. [Crossref]

9. Sung HY, Cheung DY, Cho SH, Kim JI, Park SH, et al. (2009) Polyps in the gastrointestinal tract: discrepancy between endoscopic forceps biopsies and resected specimens. Eur J Gastroenterol Hepatol. 21(2): 190-5. [Crossref]

10. Nirav Thosani, Harvinder Singh, Asha Kapadia, Nobuo Ochi, Jeffrey H. Lee, et al. (2012) Diagnostic accuracy of EUS in differentiating mucosal versus submucosa invasion of superficial esophageal cancers: a systematic review and meta-analysis. Gastrointest Endosc, 75(2): 242-253. [Crossref]

11. Ji Min Park, Chang Wook Ahn, Xian Yi, Hoon Hur, Kee Myung Lee, et al. (2011) Efficacy of Endoscopic Ultrasonography for Prediction of Tumor Depth in Gastric Cancer. J Gastric Cancer. 11(2): 109-115. [Crossref]

12. Tanabe R, Higaki S, Gondo T, Sakaida I. (2012) Preoperative evaluation of early colorectal cancer using an ultrasound mini probe. Hepato-gastroenterology 59 (118): 1794-9. [Crossref]

13. Christian Jenssen, Maria Victoria Alvarez-Sánchez, Bertrand Napoléon, Siegbert Faiss. (2012) Diagnostic endoscopic ultrasonography: Assessment of safety and prevention of complications. World J Gastroenterol. 18(34): 4659-4676. [Crossref]

14. Euscher ED, Niemann TH, Lucas JG, Kurokawa AM, Frankel WL. (2001) Large colorectal adenomas. An approach to pathologic evaluation. Am J Clin Pathol. 116(3): 336-40. [Crossref]

15. Scott R Steele, Eric K Johnson, Bradley Champagne, Brad Davis, Sang Lee, David Rivadeneira, et al. (2013) Endoscopy and polyps-diagnostic and therapeutic advances in management. World J Gastroenterol. 19(27): 4277-4288. [Crossref]

16. Sheehan KM, O'Connell F, O'Grady A, Conroy RM, Leader MB,et al. (2004) The relationship between cyclooxygenase-2 expression and characteristics of malignant transformation in human colorectal adenomas. Eur J Gastroenterol Hepatol. 16(6): 619-25. [Crossref]

17. O'Brien MJ, Winawer SJ, Zauber AG, Gottlieb LS, Sternberg SS, et al. (1990) The National Polyp Study. Patient and polyp characteristics associated with high-grade dysplasia in colorectal adenomas. Gastroenterology. 98(2): 371-9. [Crossref]

18. Thosani N, Singh H, Kapadia A, Ochi N, Lee JH, et al. (2012) Diagnostic accuracy of EUS in differentiating mucosal versus submucosal invasion of superficial esophagealcancers: a systematic review and meta-analysis. Gastrointest Endosc. 75(2): 242-53. [Crossref]

19. Park JM, Ahn CW, Yi X, Hur H, Lee KM, et al. (2011) Efficacy of endoscopic ultrasonography for prediction of tumor depth in gastric cancer.. J Gastric Cancer 11(2): 109-15. [Crossref]

20. Kiyonori Kobayashi, Mitsuhiro Kida, Tomoe Katsumata, Shigeru Yoshizawa, Kaoru Yokoyama, et al. (2003) Clinical role of endoscopic ultrasonography for the diagnosis of early colorectal cancer and selecting the treatment procedure. Dig Endosc, 15(4): 298-305.

21. Gavin C Harewood, Maurits J Wiersema, Heidi Nelson, Robert L Maccarty, Janet E Olson, et al. (2002) A prospective, blinded assessment of the impact of preoperative staging on the management of rectal cancer. Gastroenterology. 123(1): 24-32. [Crossref]

22. Hawes RH. (1993) New staging techniques: Endoscopic ultrasound. Cancer. 71(suppl): 4207- 4213. [Crossref]

23. InoueH. (2001) Magnification endoscopy in the esophagus and stomach. Digestive Endoscopy. 13(Suppl 1): S40-41.

24. ArimaM, TadaM, ArimaH. (2005) Evaluation of microvascular patterns of superficial esophageal cancers by magnifying endoscopy. Esophagus, 2(4): 191197.

25. Tatsuya Yoshida, Hiroshi Kawachi, Keita Sasajima, Akira Shiokawa, shin-ei Kudo. (2005) The clinical meaning of a nonstructural pattern in early gastric cancer on magnifying endoscopy. Gastrointest Endosc. Gastrointestinal Endoscopy. 62(1): 48-54. [Crossref]

26. Uedo N, Fujishiro M, Goda K, Hirasawa D, Kawahara Y, et al. (2011) Role of narrow band imaging for diagnosis of early-stage esophagogastric cancer: curren consensus of experienced endoscopists in Asia-Pacific region. Dig Endosc. 23 Suppl 1: 58-71. [Crossref]

27. Hewett DG, Kaltenbach T, Sano Y, Tanaka S, Saunders BP, et al (2012) Validation of simple classification system for endoscopic diagnosis of small colorectal polyps using narrow-band imaging. Gastroenterology. 143(3): 599-607. [Crossref]

28. Hayashi N, Tanaka S, Hewett DG, Kaltenbach TR, Sano Y, et al. (2013) Endoscopic prediction of deep submucosal invasive carcinoma: validation of the narrow-band imaginginternational colorectal endoscopic (NICE) classification. Gastrointest Endosc. 78(4): 625-32. [Crossref]

\section{Citation:}

Yanliu Chu, Ranran Wang, Tian Li, Xiuli Qiao, Xiaofeng Wang, Feng Liu, Xiaozhong Gao, Songyang Yu (2019) EUS in the Management of High-Risk Gastrointestinal Precancerous Lesions before Endoscopic Resection. J Clin Res Med Volume 2(2): 1-4. 